\title{
ĐẶC ĐIỂM LÂM SÀNG VÀ SIÊU ÂM TRƯớC MỔ BỆNH NHÂN THAY VAN ĐỘNG MẠCH CHỦ CƠ HỌC SORIN BICARBON TẠI BỆNH VIỆN TIM HÀ NỘI
}

\author{
Tạ Hoàng Tuấn ", Đặng Hanh Sơn "Đoàn Quốc Hung **
}

\section{TÓM TẮT:}

Tổn thương van động mạch chủ thường gặp trong các bệnh van tim. Bệnh tiến triển âm thầm hầu như không có biểu hiện triệu chứng lâm sàng. Mục tiêu: Nhận xét đặc điểm lâm sàng và siêu âm trước mổ của bệnh nhân thay van ĐMC cơ học Sorin Bicarbon tại Bệnh viện Tim Hà Nội. Đối tượng và phương pháp nghiên cứu: Mô tả cắt ngang. Đối tượng gồm tất cả bệnh nhân thay van ĐMC cơ học Sorin Bicarbon giai đoạn 2009-2014. Kết quả: Tuổi 20 đến 60 tuổi $(81,8 \% \%)$, tuổi trung bình 40,5 $\pm 10,3$, nam chiếm $71,43 \%$. Lâm sàng: khó thở 37,66\%, đau ngực 29,87\%, thổi tâm trương: $71,43 \%$. NYHA $\geq$ II: 92,21\%. Siêu âm: Hở van: 44,81\%, hẹp van: 27,27\%, hẹp hở van: 27,92\%, vôi hóa:48,05\%. Van ĐMC hai lá: 25,97\%; EF: $62,45 \pm 9,25 \%$, Dd: $58,12 \pm 10,5$ mm. Kết luận: Bệnh nhân tuổi trung niên, trung bình:40,5 $\pm 10,3$. Tại thời điểm trước mổ NYHA $\geq 2$. Siêu âm tim: Vôi hóa: $48,05 \%$. Chức năng thất trái $\mathrm{EF}: 62,45 \pm 9,25 \%$. Từ khóa: thay van động mạch chủ, Sorin Bicarbon

\section{SUMMARY:}

Aortic valve lesions are relatively common in valvular heart disease. The disease progresses silently almost no clinical symptoms. Objective: Reviews clinical characteristics and preoperative ultrasound of patients with mechanical valve replacement aortic Sorin Bicarbon at Hanoi Heart Hospital. Patients and Methods: Cross-sectional descriptive. Subjects were 154 patients with mechanical valve replacement aortic Bicarbon Sorin during from 2009 to 2014. Results: Mean age was $40,5 \pm 10,3$ (20 to 60 years old: $81,8 \%$ ), $71,43 \%$ male. Clinical signes were: dyspnea $37,66 \%$, chest pain $29,87 \%$, diastolic murmur 71,43\%. NYHA $\geq$ II 92,21\%. Echocardiography: aortic regurgitation $44,81 \%$, aortic stenosis $27,27 \%$, aortic regurgitation and stenosis $27,92 \%$, calcification $48,05 \%$. Bicuspid aortic valve $25,97 \%$; EF: $62.45 \pm 9.25 \%$, Dd $5812 \pm 10.5 \mathrm{~mm}$.

Conclusion: Patients with mean age $40,5 \pm 10,3$. At the time of preoperative NYHA $\geq \mathrm{II}: 9221 \%$, calcification $48,05 \%$, left ventricular function $62,45 \pm 9,25 \%$.

Key words: aortic val replacement, Sorin Bicarbon* .

\section{I. ĐẠT VẤN ĐỀ}

Bệnh van động mạch chủ (ĐMC) là một bệnh tim khá phổ biến trên thế giới. Tổn thương van ĐMC có thể gặp là hẹp van ĐMC, hở van ĐMC và hẹp hở phối hợp [1]. Nguyên nhân gây tổn thương van ĐMC có nhiều loại như thấp tim, Osler, bẩm sinh, thoái hoá... Tại Việt Nam và một số nước đang phát triển thì nguyên nhân chủ yếu là thấp tim [1],[2]. Trái lại, ở các nước phát triển nguyên nhân chủ yếu là thoái hoá và bệnh van ĐMC bẩm sinh [3],[4]. Chẩn đoán bệnh van

\footnotetext{
* Bệnh viện Tim Hà Nội

** Bệnh viện Hũu nghị Việt Đức

Người chịu trách nhiệm khoa học: PGS.TS. Đoàn Quốc Hung Ngày nhận bài: 05/04/2016 - Ngày Cho Phép Đăng: 05/05/2016

Phản Biện Khoa học: PGS.TS. Đặng Ngọc Hùng GS.TS. Bùi Đúc Phú
} 
ĐMC dựa vào các triệu chứng lâm sàng và cận lâm sàng. Trong đó siêu âm tim có vai trò đặc biệt quan trọng trong việc chẩn đoán xác định, mức độ tổn thương, hậu quả do bệnh van ĐMC và còn giúp đưa ra chỉ định điều trị cũng như theo dõi lâu dài sau mổ. Tiến triển của bệnh van ĐMC thường kéo dài và không có biểu hiện lâm sàng, khi bệnh nhân có biểu hiện như đau ngực, khó thở... thì mức độ tổn thương van đã nặng, do vậy việc chẩn đoán bệnh van ĐMC sớm đóng vai trò quan trọng để đưa ra chỉ định điều trị phù hợp [1],[2],[5],[6],[7]. Bệnh van ĐMC gây ra suy tim trái sau đó suy tim toàn bộ, chính vì vậy phải có chiến lược chẩn đoán và điều trị sớm. Xuất phát từ thực tế trên chúng tôi tiến hành đề tài này nhằm rút ra nhận xét đặc điểm lâm sàng và siêu âm trước mổ BN thay van ĐMC Sorin Bicarbon tại Bệnh viện Tim Hà Nội.

\section{II. ĐỐI TƯợNG VÀ PHƯƠNG PHÁP NGHIÊN CÚ̉U}

2.1. Đối tượng: Gồm bệnh nhân $(\mathrm{BN})$ tổn thương van $\mathrm{ĐMC}$ đơn thuần chẩn đoán và điều trị tại Bệnh viện tim Hà Nội.

2.2. Phương pháp: Mô tả hồi cứu trong thời gian từ $1 / 2009$ đến $12 / 2014$.

2.3. Quy trình nghiên cứu: Đánh giá $\mathrm{BN}$ về các mặt: lâm sàng (tuổi, giới, triệu chứng, bệnh lý kèm theo), cận lâm sàng ( siêu âm tim, đánh giá tổn thương van, chức năng tim), các xét nghiệm khác. Tổng kết dữ liệu bằng bệnh án nghiên cứu. Xử lý bằng phần mềm SPSS 19.0.

\section{KẾT QUẢ}

3.1. Đặc điểm chung: Từ $1 / 2009$ đến 12/2014, Bệnh viện Tim Hà Nội đã phẫu thuật 231 $\mathrm{BN}$ thay van ĐMC đơn thuần, trong đó có $154 \mathrm{BN}$ thay van ĐMC cơ học Sorin Bicarbon đủ tiêu chuẩn nghiên cứu với các đặc điểm như sau:

Bảng 3.1. Phân bố đối tự̛ng nghiên cứu theo nhóm tuổi và giới (n=154)

\begin{tabular}{|c|c|c|c|}
\hline & & Số BN & Tỷ lệ \% \\
\hline \multirow{3}{*}{ Nhóm tuổi } & $<20$ & 12 & 7,8 \\
\cline { 2 - 4 } & $20-39$ & 41 & 26,6 \\
\cline { 2 - 4 } & $40-59$ & 85 & 55,2 \\
\cline { 2 - 4 } & $\geq 60$ & 16 & 10,4 \\
\cline { 2 - 4 } & Tổng & $\mathbf{1 5 4}$ & $\mathbf{1 0 0}$ \\
\hline \multirow{2}{*}{ Giới tính } & Nam & 110 & 71,43 \\
\cline { 2 - 4 } & Nữ & 44 & 28,57 \\
\cline { 2 - 4 } & Tổng & $\mathbf{1 5 4}$ & $\mathbf{1 0 0}$ \\
\hline
\end{tabular}

Nhân xét: Bệnh lý van ĐMC trong nghiên cứu của chúng tôi gặp chủ yếu ở lứa tuổi 20 đến 60 tuổi $(81,8 \%)$, tuổi trung bình là 40,5 $\pm 10,3$, lớn nhất là 62 tuổi và nhỏ nhất là 10 tuổi. Về giới, nam $(71,43 \%)$ nhiều hơn nữ $(28,57 \%)$. 


\section{2. Đặc điểm lâm sàng}

Bảng 3.2. Mức độ suy tim của bệnh nhân trước mổ $(N=154)$

\begin{tabular}{|c|c|c|}
\hline NYHA & Số BN & Tỷ lệ \% \\
\hline I & 12 & 7,79 \\
\hline II & 104 & 67,53 \\
\hline III & 35 & 22,73 \\
\hline IV & 3 & 1,95 \\
\hline Tổng & $\mathbf{1 5 4}$ & $\mathbf{1 0 0}$ \\
\hline
\end{tabular}

Nhân xét: Mức độ suy tim theo NYHA từ độ II trở lên trong nghiên cứu là 92,21\% trong đó NYHA II là $67,53 \%$, NYHA III là 22,73\%, NYHA IV là 1,95\%.

Bảng 3.3. Các triệu chứng lâm sàng chính của bệnh nhân

\begin{tabular}{|l|c|c|}
\hline \multicolumn{1}{|c|}{ Triệu chứng } & n & Tỷ lệ \% \\
\hline Đau ngực & 46 & 29,87 \\
\hline Hồi hộp & 12 & 7,79 \\
\hline Tim loạn nhịp & 25 & 16,23 \\
\hline Tiếng thổi bệnh lý & 110 & 71,43 \\
\hline Gan to & 16 & 10,39 \\
\hline
\end{tabular}

\section{3. Đặc điểm cận lâm sàng}

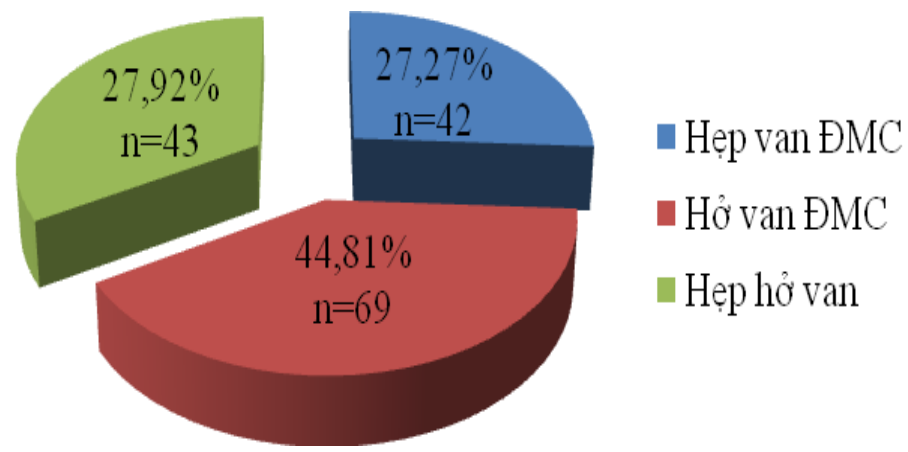

Biểu đồ 3.1. Hình thái tổn thương van ĐMC trên siêu âm tim

Nhân xét: Hình thái tổn thương van ĐMC trên siêu âm tim tương đương nhau $(27,27 \%$ hẹp van, $44,81 \%$ hở van và $27,92 \%$ hẹp hở van phối hợp). 
Bảng 3.4. Mức độ tổn thương van ĐMC

\begin{tabular}{|c|c|c|c|c|c|}
\hline \multicolumn{2}{|c|}{ Chỉ số } & $\begin{array}{c}\text { Hẹp van } \\
(n=42)\end{array}$ & $\begin{array}{c}\text { Hở van } \\
(n=69)\end{array}$ & $\begin{array}{c}\text { Hẹp hở van } \\
(n=43)\end{array}$ & Chung \\
\hline \multicolumn{2}{|c|}{$\begin{array}{l}\text { Chênh áp tối đa qua van } \\
(\mathrm{mmHg})\end{array}$} & $\begin{array}{c}102,51 \pm 24,62 \\
(62-153)\end{array}$ & $\begin{array}{c}21,83 \pm 14,79 \\
(3,2-45)\end{array}$ & $\begin{array}{c}63,19 \pm 28,28 \\
(5,8-76)\end{array}$ & $56,19 \pm 39,24$ \\
\hline \multirow{4}{*}{ Mức độ hở } & $\leq 1 / 4$ & 42 & 0 & 0 & \multirow{4}{*}{$2,4 \pm 1,1$} \\
\hline & $2 / 4$ & 0 & 0 & 5 & \\
\hline & $3 / 4$ & 0 & 29 & 24 & \\
\hline & $4 / 4$ & 0 & 48 & 14 & \\
\hline
\end{tabular}

Bảng 3.5. Kết quả trên siêu âm tim trước mổ

\begin{tabular}{|c|c|c|c|c|}
\hline \multicolumn{2}{|c|}{ Các thông số } & Kết quả & Giá trị bình thường & $\mathbf{p}$ \\
\hline \multicolumn{2}{|c|}{ NT (mm) } & $37,14 \pm 5,13$ & 31 & $<0,0001$ \\
\hline \multicolumn{2}{|c|}{ ĐMC (mm) } & $31,27 \pm 3,74$ & 28 & $<0,0001$ \\
\hline \multicolumn{2}{|c|}{$\mathrm{Dd}(\mathrm{mm})$} & $58,12 \pm 10,5$ & 46 & $<0,0001$ \\
\hline \multicolumn{2}{|c|}{ VLTTTr (mm) } & $11,54 \pm 1,97$ & 7,5 & $<0,0001$ \\
\hline \multicolumn{2}{|c|}{ TSTTTTr $(\mathrm{mm})$} & $10,36 \pm 3,2$ & 7 & $<0,0001$ \\
\hline \multicolumn{2}{|c|}{$\mathrm{EF}(\%)$} & $62,45 \pm 9,25$ & 63 & 0,1416 \\
\hline \multicolumn{2}{|c|}{ KLTT (g) } & $313,16 \pm 115,46$ & & \\
\hline \multirow{3}{*}{$\begin{array}{c}\text { Chỉ số KLTT } \\
\qquad\left(\mathrm{g} / \mathrm{m}^{2}\right)\end{array}$} & Nam & 231,17 & 134 & $<0,0001$ \\
\hline & Nữ & 173,24 & 110 & $<0,0001$ \\
\hline & Tổng & $206,25 \pm 68,46$ & & \\
\hline \multicolumn{2}{|c|}{ Tỷ lệ vôi hóa (\%) } & $74 / 154(48,05 \%)$ & & \\
\hline \multirow{2}{*}{$\begin{array}{l}\text { Tổn thương } \\
\text { kết hợp } \\
\text { (mức độ nhẹ) }\end{array}$} & Van HL & $30 / 154(19,48 \%)$ & & \\
\hline & Van BL & $20 / 154(12,99 \%)$ & & \\
\hline
\end{tabular}

Bảng 3.6. Kích thước thất trái với tùng hình thái tổn thương van ĐMC

\begin{tabular}{|c|c|c|c|c|}
\hline $\begin{array}{l}\text { Kích thước } \\
\text { thất trái }\end{array}$ & $\begin{array}{c}\text { Hở van }(n=69) \\
\text { (1) }\end{array}$ & $\begin{array}{c}\text { Hẹp van } \\
(n=42) \\
(2)\end{array}$ & $\begin{array}{c}\text { Hẹp hở van } \\
(n=43) \\
(3)\end{array}$ & $\mathrm{P}<\mathbf{0 , 0 5}$ \\
\hline Chỉ số KLTT $\left(\mathrm{g} / \mathrm{m}^{2}\right)$ & $242,1 \pm 73,2$ & $168,2 \pm 50,4$ & $189,2 \pm 65,4$ & $1-2 ; 1-3$ \\
\hline Dd (mm) & $66,1 \pm 8,6$ & $45,3 \pm 4,4$ & $55,7 \pm 9,5$ & $1-2 ; 1-3 ; 2-3$ \\
\hline VLTttr (mm) & $10,5 \pm 2,6$ & $12,3 \pm 1,9$ & $11,9 \pm 3,7$ & $1-2 ; 1-3$ \\
\hline TSTTttr (mm) & $10,1 \pm 1,7$ & $11,3 \pm 2,6$ & $10,9 \pm 2,7$ & \\
\hline
\end{tabular}




\section{IV.BÀN LUẬN}

\section{1. Đặc điểm lâm sàng}

4.1.1. Tuổi và giới: Bệnh lý van ĐMC trong nghiên cứu của chúng tôi gặp chủ yếu ở lứa tuổi 20 đến 60 tuổi $(81,8 \%)$, tuổi trung bình là 40,5 $\pm 10,3$, lớn nhất là 62 tuổi và nhỏ nhất là 10 tuổi (Bảng 3.1). Tuổi trung bình của $\mathrm{BN}$ trong nghiên cứu của chúng tôi thấp hơn so với các nghiên cứu của các tác giả ở châu Âu và Bắc Mỹ. Tại các quốc gia này, phẫu thuật thay van ĐMC chủ yếu ở BN cao tuổi do vôi hóa van ĐMC. Vitale và cộng sự thấy rằng thay van ĐMC chủ yếu gặp ở đối tượng có tuổi từ 60 đến 80 [6]. Theo Mecozzi, tuổi trung bình là 67,4 , trong đó khoảng tuổi từ 20 đến 60 chỉ chiếm $29,5 \%$, trên 60 tuổi chiếm 70,5\% [8]. Nghiên cứu của $B$. Borman và cộng sự [7], tuổi trung bình của $\mathrm{BN}$ tại thời điểm phẫu thuật là 67,3 .

Tại các các quốc gia đang phát triển trong đó có Việt Nam, những nước mà thấp tim còn chiếm tỷ lệ cao, phẫu thuật thay van ĐMC thường được thực hiện cho những $\mathrm{BN}$ tổn thương van tim do thấp ở tuổi trung niên hoặc trẻ tuổi. Nghiên cứu của Bahnson cho biết tuổi trung bình trong nhóm $\mathrm{BN}$ thay van ĐMC cơ học là $32,1 \pm 12,5$ [9]. Donald B.D trong nghiên cứu của mình cho biết tuổi trung bình của $\mathrm{BN}$ là 35,7 $\pm 2,7$ [10]. Tại Việt Nam, Phạm Thái Hưng nghiên cứu kết quả phẫu thuật thay van ĐMC với tuổi trung bình $35,4 \pm 5,3$ [11]. Như vậy kết quả nghiên cứu của chúng tôi cũng phù hợp với các tác giả này. Chúng tôi có $1 \mathrm{BN} 10$ tuổi, $1 \mathrm{BN} 11$ tuổi, các $\mathrm{BN}$ này đều phải thay van do tổn thương van quá nặng, không có chỉ định bảo tồn. Việc thay van cho nhóm đối tượng này bắt buộc phải dùng van số nhỏ (cỡ 17) và yêu cầu mở rộng vòng van trong 1 số trường hợp.

Về giới, nam $(71,43 \%)$ nhiều hơn nữ $(28,57 \%)$, kết quả này phù hợp với các nghiên cứu về bệnh lý van ĐMC ở cả nước ngoài và trong nước, do bệnh lý tim mạch thường xảy ra ở nam giới [2],[5],[7],[11],

\subsubsection{Một số triệu chúng lâm sàng}

Mức độ suy tim theo NYHA từ độ II trở lên trong nghiên cứu là $92,21 \%$ trong đó NYHA II là $67,53 \%$, NYHA III là 22,73\%, NYHA IV là 1,95\%. Khi xuất hiện triệu chứng có $37,66 \% \mathrm{BN}$ biểu hiện khó thở nhưng tới thời điểm phẫu thuật đều có biểu hiện suy tim trên lâm sàng. Theo Phạm Thái Hưng trong nghiên cứu về thay van ĐMC ở $\mathrm{BN}$ hở van ĐMC do thấp tim, cũng cho thấy, tất cả $\mathrm{BN}$ trước mổ đều suy tim mức độ NYHA II trở lên, trong đó NYHA III là 36,92\%, không có trường hợp nào NYHA IV [11]. Theo Donald B.D, 96\% BN trước mổ suy tim NYHA II trở lên, nhưng tỷ lệ suy tim mức độ vừa và nặng rất cao (36\% NYHA III, $10 \%$ NYHA IV) [10]. Theo Whitaker, tỷ lệ suy tim NYHA II trở lên là $90 \%$, nhưng tỷ lệ suy tim mức độ nặng là 27,7\%[12]. Theo Vitale, tỷ lệ suy tim NYHA II trở lên là $87,1 \%$, trong đó NYHA III là $35,5 \%$ [6]. Tỷ lệ suy tim vừa, nặng trong nghiên cứu của chúng tôi tương tự với tác giả trong nước, nhưng thấp hơn các tác giả nước ngoài, điều này là do độ tuổi tại thời điểm phẫu thuật trong bệnh lý van ĐMC tại Việt Nam thấp, ít bệnh lý toàn thân nặng kèm theo, đặc biệt là ít có bệnh lý ĐMV thực thể.

Trong bệnh lý van ĐMC, tổn thương van dẫn đến suy tim trái, gây ứ máu ở phổi, biểu hiện khó thở khi gắng sức, nhưng trong nghiên cứu của chúng tôi có $10,39 \%$ có dấu hiệu gan to khi thăm khám, điều này chứng tỏ tại thời điểm phẫu thuật một số bệnh nhân đã biểu hiện suy tim toàn bộ.

Khi nghe tim ghi nhận $71,43 \%$ có tiếng thổi bệnh lý (thổi tâm thu hoặc thổi tâm trương ở ổ van ĐMC), như vậy chỉ 2/3 BN khi nghe tim phát hiện được tiếng thổi bệnh lý. Trong hẹp van ĐMC, tiếng 
thổi tâm thu rất dễ phát hiện, nhưng trường hợp hẹp rất khít có thể sẽ không nghe thấy thổi, còn tiếng thổi tâm trương trong hở van ĐMC là tiếng thổi nhẹ do đó cũng không dễ xác định.

Các triệu chứng lâm sàng nêu trên đặc biệt là mức độ suy tim theo NYHA và đau ngực rất có giá trị trong việc chẩn đoán và chỉ định phẫu thuật cho bệnh nhân được chính xác và kịp thời.

\section{2. Đặc điểm siêu âm tim}

Chỉ định phẫu thuật chủ yếu dựa trên kết quả siêu âm tim. Các thăm dò cận lâm sàng khác có vai trò hỗ trợ trong chẩn đoán và điều trị.

Siêu âm tim là tiêu chuẩn vàng để đánh giá tình trạng lá van, thể bệnh, mức độ nặng, theo dõi để quyết định thời điểm phẫu thuật và theo dõi sau mổ.

Hình thái tổn thương van ĐMC trên siêu âm tim tương đương nhau $(27,27 \%$ hẹp van, 44,81\% hở van và $27,92 \%$ hẹp hở van phối hợp). Tỷ lệ này tương đương với các tác giảc khi nghiên cứu về thay van ĐMC cơ học ở người trẻ tuổi: theo Vitale thì hẹp van 45,8\%, hở van 40,7\%, hẹp hở van 13,5\% [6]; theo Donald B.D hẹp van 41\%, hở van $32 \%$, hẹp hở van $27 \%$ [10].

Thứ nhất, đối với nhóm bệnh nhân chỉ định mổ do hở van ĐMC thì các chỉ số quan trọng để đánh giá và đưa ra chỉ định phẫu thuật cho bệnh nhân là chức năng tâm thu thất trái $(\mathrm{EF})$, đường kính thất trái cuối tâm trương (hoặc đường kính thất trái cuối tâm thu). Trong nghiên cứu này chúng tôi dùng chỉ số đường kính thất trái cuối tâm trương có kết quả là $66,1 \pm 8,6$, giá trị này cao hơn chỉ số bình thường một cách có ý nghĩa thống kê và có vai trò quan trọng trong việc chỉ định mổ theo Khuyến cáo Hội tim mạch Việt nam 2008. Đường kính thất trái có sự khác biệt rõ rệt giữa 3 hình thái tổn thương: lớn nhất ở nhóm hở van, tiếp đến là nhóm hẹp hở, nhỏ nhất hở nhóm hẹp van; bề dày VLT lớn nhất ở nhóm hẹp; chỉ số KLTT lớn nhất ở nhóm hở van.
Điều này phù hợp với tổn thương giải phẫu sinh lý trong từng hình thái tổn thương. Trong hẹp van ĐMC, gây nên quá tải áp lực cho tim trái dẫn đến dày thất trái. Ngược lại, trong hở van $\mathrm{ĐMC}$, trong thì tâm trương máu từ ĐMC sẽ phụt ngược về thất trái cộng với lượng máu từ nhĩ trái xuống làm quá tải thể tích cho thất trái, theo định luật Starling, thất trái sẽ tăng sức co bóp, vì vậy cung lượng tim và phân suất tống máu sẽ tăng, lâu dần thất trái sẽ giãn và phì đại [3],[4]. Chỉ số KLTT là 206,25 g/m², mức độ phì đại cơ thất trái trước mổ của $\mathrm{BN}$ với bệnh lý van ĐMC của chúng tôi tương đương với các tác giả khác: Phạm Thái Hưng [11] là $214 \pm 65 \mathrm{~g} / \mathrm{m}^{2}$,của Catherine [13] là $199 \pm 79 \mathrm{~g} / \mathrm{m}^{2}$.

Thứ hai, trong trường hợp hẹp van ĐMC thì chỉ số trên siêu âm quyết định chỉ định mổ là chênh áp tối đa qua van ĐMC và diện tích lỗ van ĐMC. Trong nhóm hẹp van đơn thuần thì chênh áp tối đa qua van cao nhất là: $102,51 \pm 24,62$, khác biệt với nhóm hở van $(21,83 \pm 14,79)$ và hẹp hở van $(63,19 \pm$ 28,28). Riêng chỉ số diện tích lỗ van không được đo thường qui trên tất cả $\mathrm{BN}$ nghiên cứu nên chúng tôi không đề cập để thống kê và nhận xét trong nghiên cứu này.

Tổn thương van tim phối hợp, tổn thương van hai lá chiếm 19,48\%, van ba lá chiếm $12,99 \%$. Sở dĩ có tỷ lệ tổn thương van phối hợp cao trong nghiên cứu của chúng tôi là do phần lớn bệnh lý van tim tại Việt Nam do thấp tim, thương tổn nhiều van là đặc trưng của tổn thương van tim do thấp [5],[14],[15]. Tuy nhiên các tổn thương này đều ở mức độ nhẹ và không cần phải can thiệp.

\section{KẾT LUẬN}

Qua nghiên cứu 154 bệnh nhân thay van ĐMC cơ học Sorin Bicarbon tại bệnh viện Tim Hà Nội từ năm 2009 đến 2014, chúng tôi có các kết luận như sau: Đa phần trẻ tuổi (lứa 20-60 tuổi chiếm $81,8 \%$ ). Trước mổ hầu hết $\mathrm{BN}$ có biểu hiện 
suy tim trên lâm sàng (NYHA từ II trở lên chiếm $92,21 \%, 10,39 \%$ suy tim toàn bộ). Triệu chứng khó thở chiếm 37,66\% và đau ngực là 29,87\%. Biểu hiện tim trái giãn ( $\mathrm{Dd} 58,12 \pm 10,5 \mathrm{~mm}$ ), phì đại cơ thất trái (chỉ số KLTT 206,25 $\mathrm{g} / \mathrm{m}^{2}$ ). Chênh áp tối đa qua van trước mổ: $102,51 \pm 24,62 \mathrm{mmHg}$. Chức năng tâm thu thất trái trước mổ còn bình thường ( $\mathrm{EF}$ $62,45 \pm 9,25 \%$ ). Tỷ lệ vôi hóa van trên siêu âm tim là $48,05 \%$. Tỷ lệ hẹp van ĐMC là 27,27\%, hở van $44,81 \%$, hẹp hở van 27,92\%. Van ĐMC hai cánh chiếm $25,97 \%$.

\section{TÀI LIỆ THAM KHẢO}

1.Lawrence H.C (2008), "Pathophisiology of aortic valve disease", Cardiacsurgery in adult, T. Mihaljevic, Editors, The McGraw-Hill Companies:850-880

2.Đặng Hanh Đệ, Nguyễn Hữu Ước (2002), "Chi định điều trị ngoại khoa trong một số bệnh van tim do thấp", Thấp tim và bệnh tim do thấp, NXB Y học, Hà nội, pp. 288-314.

3.Kirklin J.W (2007), "Aortic valve disease", Cardiac surgery in adult 3th edition, Churchill livingstone, pp. 491-571.

4.Stuart W.J, Michael M.M (2004), "The choice of valve protheses", J Am Coll Cardiol, 44: pp. 389-390.

5.Phạm Nguyễn Vinh (2003), "Hẹp van động mach chü", Bệnh học tim mạch NXB Y học, Thành phố Hồ Chí Minh, pp. 38-48.

6.Vitale, G. Cappabianca, G. Visicchio, C. Fondacone, V. Paradiso, G. Mannatrizio,L. de Luca Tupputi Schifosa "Midterm evaluation of the Sorin Bicarbon heart valve prothesis: singlecenter experience",.The Annals of Thoracic Surgery 2004; 77: 527-531

7.B. Borman, C. De Riberolles. Eur J "Sorin
Bicarbon bileaflet valve: a ten year experiences", Cardio Thorac Surg 2003; 23(1):86-92

8.Mecozzi, A.D. Milano, M. DeCarlo, F. Sorrentino, S. Pratali, C. Nardi, U. Bortolotti "Intravascular hemolysis in patients with newgeneration prosthetic heart valves: a prospective study".J Thorac Cardiovas Surg 2002; 123(3):550,6

9.Bahnson H.T, Spencer F.C, Busse E.F.G, David J.G (1960), "Cusp replacement and coronary artery perfusion in open operations on the aortic

10.Donald B.D, Gary Hartstein (1997), "Aortic valve replacement", Cardiac surgery: operative technique, Anne S. Patterson, pp. 214-251.

11.Phạm Thái Hưng, Lê Ngọc Thành, Đặng Hanh Đệ (2009), "Đánh giá kết quả sớm sau phẫu thuật thay van động mạch chủ tại bệnh viện Việt Đức - Hà Nội", Y học Việt Nam, 1(3): pp. 48-53.

12.Whitaker, R.K. Walesby.J El Oakley, Micheal AB "A single centre experience on the Bicarbon heart valve proshesis: long term results". Heart Valve Dis 2004; 13(1):97-102

13.Catherine M.O (2006), "Disease severity and timing of intervention", J.Am.Coll.Cardiol, 47: pp. 2141-2151.

14.Blase S.C (2002), "Aortic stenosis", N ENGL J MED, 346(9): pp. 677-682. valve ", Ann Surg, 152: pp. 494.

15.Harken D.E, Soroff H.S, Taylor W.J, Lefemine A.A, Gupta S.K, Lunzer

S (1960), "Partial and complete prostheses in aortic insufficiency", Thorac Caridovasc Surg, 40: pp. 744 . 